\title{
Selective Spinal Nerve Block in Ilioinguinal, lliohypogastric and Genitofemoral Neuralgia
}

\author{
Ahmet KALE 1 , Hande GURBUZ AYTULUK ${ }^{2,3}$, Isa CAM ${ }^{4}$, Gulfem BASOL ${ }^{1}$, Bahar SUNNETCI ${ }^{1}$ \\ ${ }^{1}$ University of Health Sciences, Derince Training and Research Hospital, Department of Gynecology and Obstetrics, Kocaeli, Turkey \\ ${ }^{2}$ University of Health Sciences, Derince Training and Research Hospital, Department of Anesthesiology and Reanimation, Kocaeli, Turkey \\ ${ }^{3}$ Kocaeli University Faculty of Medicine, Department of Anatomy, Kocaeli, Turkey \\ ${ }^{4}$ University of Health Sciences, Derince Training and Research Hospital, Department of Radiology, Kocaeli, Turkey \\ This study has been presented as an oral presentation at the 15th Pain Congress with International Participation 2018, Antalya.
}

Corresponding author: Hande GURBUZ AYTULUK handegrbz@gmail.com

\section{ABSTRACT}

AIM: To seek the efficacy of selective spinal nerve blocks in the treatment of groin pain that are irresponsive to peripheral nerve blocks.

MATERIAL and METHODS: This retrospective study comprised 17 patients with ilioinguinal, iliohypogastric, and genitofemoral neuralgias treated between 2017 and 2018.

RESULTS: All patients received diagnostic peripheral nerve blocks and/or TAP blocks with blind or ultrasound-guided techniques. Four patients had ineffectual peripheral nerve blocks, after which they underwent T12 and L1 selective spinal nerve blocks. All four patients had satisfactory results.

CONCLUSION: If distal peripheral nerve blocks are ineffective, an upper level nerve lesion, a lesion in the lumbar plexus or an L1 radiculopathy should be considered in ilioinguinal, iliohypogastric, and genitofemoral neuralgias. Upper level nerve blocks should be performed before deciding on surgery.

KEYWORDS: Genitofemoral nerve, Groin pain, Iliohypogastric nerve, Ilioinguinal nerve, Nerve block, Pain, Selective spinal nerve block

\section{- INTRODUCTION}

$\mathrm{I}$

lioinguinal (II), iliohypogastric (IH), and genitofemoral (GF) neuralgias present with pain or paresthesia in the respective innervation areas of the nerves. Clinically significant moderate-to-severe pain affects physical activity, social interactions, and life quality. The clear majority of II, IH, and GF neuralgias are iatrogenic, as a result of mechanical damage (direct damage) or entrapment (scar tissue, mesh, or sutures) of the nerves during lower abdominal surgeries (26), including appendectomy, hysterectomy $(6,7)$, cesarean delivery, and inguinal herniorrhaphy (13,32). Other potential causes of these neuropathies include psoas abscess, Pott's disease, prolonged wearing of constrictive clothing, blunt abdominal trauma, visceral adhesions, T12, L1, L2 radiculopathies, and lumbar plexus pathologies (25).

\section{Anatomy}

Understanding the anatomy of the lumbar plexus and $\mathrm{II}, \mathrm{IH}$, and GF nerves is essential to perform successful blocks.

The lumbar plexus lies posterior of the psoas major muscle. It is formed by the first four lumbar ventral rami of spinal nerves, sometimes with contribution of the ventral ramus of $12^{\text {th }}$ thoracic spinal nerve. The lumbar plexus then divides into eight branches.

\begin{tabular}{llll}
\hline Ahmet KALE & (D) : 0000-0001-6059-4873 & Isa CAM & (D) : 0000-0001-9941-3603 \\
Hande GURBUZ AYTULUK (D) : 0000-0002-3562-9517 & Gulfem BASOL (D) : 0000-0001-7738-8531
\end{tabular}




\section{Iliohypogastric and llioinguinal Nerves}

The upper and larger branch of the lumbar plexus receives contributions from the ventral rami of $\mathrm{T} 12$ and $\mathrm{L} 1$, and then divides into two to form the $\mathrm{IH}$ and $\mathrm{II}$ nerves. The $\mathrm{IH}$ nerve exits the psoas muscle superior to the II nerve, and they cross the quadratus lumborum muscle in an oblique direction. They perforate the transversus abdominis muscle together at the level of the anterior superior spine.

\section{Iliohypogastric Nerve Course and Function}

The $\mathrm{IH}$ nerve runs between the internal oblique muscle and the transversus abdominis muscle then divides into two branches: the anterior cutaneous branch and the lateral cutaneous branch. The anterior cutaneous branch continues to run between the internal oblique and transversus abdominis muscles and then perforates the external oblique muscle just beyond the anterior superior iliac spine to provide cutaneous sensory innervation to the abdominal skin, groin, and superior to the pubis. The lateral cutaneous branch runs through the internal and external oblique muscles at a level superior to the iliac crest and provides cutaneous sensory innervation to the posterolateral aspects of the gluteal region. The $\mathrm{IH}$ nerve also supplies motor fibers to the internal oblique and transversus abdominis muscles.

\section{Ilioinguinal Nerve Course and Function}

The II nerve enters the internal oblique muscle, then accompanies the spermatic cord, and these pass together through the inguinal canal. The nerve then provides cutaneous sensory innervation to the superior part of the skin of the inner thigh and the root of the penis and upper part of the scrotum in men or the mons pubis and lateral part of the labia in women. II nerve also supplies motor fibers to the internal oblique and transversus abdominis muscles.

The $\mathrm{IH}$ nerve is larger than the II nerve and sometimes the II nerve may interconnect with the $\mathrm{IH}$ nerve where it enters the quadratus lumborum. Furthermore, one or both of the $\mathrm{IH}$ and II nerves may be absent (4). Accordingly, the distribution of the sensory innervation area of the II nerves varies from patient to patient, and there may be an overlap with the $\mathrm{IH}$ nerve territory.

\section{Genitofemoral Nerve Course and Function}

The GF nerve is formed by the ventral rami of $L 1$ and $L 2$ spinal nerves of the lumbar plexus. The nerve descends through the psoas muscle emerging on the muscle's anterior surface. The GF nerve passes behind the left ureter, gonadal vessels, left colic artery, and inferior mesenteric vein on the left. It passes behind the right ureter, gonadal vessels, and ileocolic artery and vein on the right. The GF nerve pierces the psoas fascia and bifurcates into the genital and femoral (crural) branches superior to the inguinal ligament.

\section{Genital Branch}

The genital branch of the GF nerve travels through the inguinal canal accompanying the spermatic cord and innervates the cremaster muscle and skin of the scrotum in men or accompanying the round ligament of the uterus and supplies sensory fibers to the mons pubis and labia majora in women.

\section{Femoral Branch}

The femoral branch of the GF nerve descends laterally to the external iliac artery and passes under the inguinal ligament. The GF nerve enters the femoral sheath lateral to the femoral artery and innervates the skin of the anterior superior femoral triangle.

In cadaveric studies, almost $50 \%$ of GF nerves showed an anatomic variation. The GF nerve bifurcates prematurely at the upper portion (rather than the mid-portion) of the anterior surface of the psoas major muscle (20\%); rarely, the genital and femoral branches do not merge into a common trunk and remain as separate nerves in their course (2).

\section{Evaluation and Treatment}

Overlapping cutaneous sensory innervations of these nerves may cause difficulty in finding the primary injured nerve. Furthermore, these three nerves are located anatomically in close proximity in the groin region, they can be injured alone or in combination in the groin area due to lower abdominal surgical procedures (12). IH, II, and GF neuralgias typically present sharp, burning, and persistent pain in the groin or upper pubic area. The physical examination may reveal hypo/hyperesthesia, paresthesia or allodynia in the nerves' respective cutaneous innervations, thus the nature of the pain is clearly neuropathic (28).

Pharmacologic treatment may include antidepressants (tricyclic antidepressants, serotonin-norepinephrine reuptake inhibitors, selective serotonin reuptake inhibitors), antiepileptics (gabapentin, pregabalin), cannabinoids, topical capsaicin, non-steroidal anti-inflammatory drugs, and botulinum toxin $A$ (3).

Differential diagnostic nerve blocks are simple techniques that can produce dramatic relief. Nerve blocks are essential to reveal which nerve or nerve combinations are affected, or to show if the nerve damage is peripheral or centrally originated (8). If IH, II, and GF nerve blocks are ineffectual, a diagnosis of lesions more proximal in the lumbar plexus or an L1 radiculopathy should be considered (30). Electromyography and magnetic resonance imaging (MRI) of the lumbar plexus are indicated in these patients to rule out lumbar plexus, epidural or vertebral pathologies. Cases in which the cause is central often respond to epidural steroid blocks. Anatomic landmark-based approaches can easily be performed for nerve blocks (23). Additionally, ultrasound, computed tomography, and MR guidance has been found to increase the accuracy of nerve blocks $(24,29)$. Diagnostic nerve blocks followed by serial therapeutic nerve blocks with local anesthetic and corticosteroid have been demonstrated to be successful in many patients (27).

Locally injected anesthetic and anti-inflammatory drugs may result in therapeutic benefit by interrupting pathways involved in nociceptor stimulation (14). Neurolytic block with small quantities of phenol, cryoneurolysis or radiofrequency ablation has been shown to provide long-term pain relief for patients with chronic pain secondary to trauma to these nerves for which conservative treatments have been in effectual $(13,22)$. 
Peripheral nerve stimulation has also been shown to be effective in $70 \%$ of patients with GF neuralgia (31).

Surgical treatment (neurectomy) is an option for which symptoms cannot be controlled by more conservative treatments $(1,16)$. If the pain persists following surgical treatment, neuroma formation should be kept in mind.

\section{MATERIAL and METHODS}

After approval of the local ethics committee (GOKAEK 2018/63), patients who were admitted to gynecology clinic for pelvic pain between 2017 and 2018 were evaluated. Medical records of seventeen patients with groin pain who were diagnosed as having $\mathrm{IH}, \mathrm{II}$, and GF neuralgia and treated with an interventional technique were analyzed. All patients were followed up at least six months following the interventional pain management. We obtained the latest information about their final condition through a physical examination in hospital and by telephone calls for those who were not able to come to hospital.

Each patient had various neuropathic symptoms and a physical examination that supported the diagnosis of neuralgia. All patients were consulted by neurosurgery, neurology, physical therapy and rehabilitation, and internal medicine clinics. Patients' ultrasound and MRI were performed in order to exclude any other pathologies. Patients who failed to respond to pharmacologic medication were treated with serial therapeutic nerve blocks with local anesthetics and corticosteroids following a diagnostic nerve block. Nerve blocks were performed using either the anatomic land-mark technique or with the guidance of ultrasound (Figures 1,2) with $35 \mathrm{mg}$ bupivacaine and $40 \mathrm{mg}$ methylprednisolone per nerve.

If the block failed, ultrasound-guided transversus abdominis plane (TAP) block was performed. If the plane block was ineffectual, we considered that the lesion was at a more proximal site of the nerve. After routine anesthetic and surgical preparations were complete, thoracic and lumbar (T12, L1) selective nerve blocks were performed (diagnostic nerve block followed by serial therapeutic nerve blocks) with local anesthetics and corticosteroids under the guidance of fluoroscopy in the operating room.

After monitorization of the patient, a 20G cannula was inserted. With the patient in the prone position with a pillow under the abdomen to decrease lordosis, the skin was prepared with an antiseptic solution, and the end plates of the targeted vertebra were aligned under fluoroscopy. The block was performed with a postero-lateral approach with a $22 \mathrm{G} 88 \mathrm{~mm}$ needle. Two patients expressed a mild transient paresthesia, then the needle was withdrawn slightly until the pain eased. After confirming an acceptable needle position (Figures 3,4), $1 \mathrm{~mL}$ of water-soluble contrast (Omnipaque ${ }^{\circledR}$ ) was injected. After satisfactory flow of contrast (distally along the nerve sheath) was observed and no evidence of epidural, subdural, subarachnoid, or intravascular spread of contrast was seen, $5 \mathrm{~mL} 0.5 \%$ bupivacaine $\left(\right.$ Buvasin $\left.^{\circledR}\right)$ and $2 \mathrm{mg}$ of dexamethasone (Dekort ${ }^{\circledR}$ ) per nerve was injected. Following removal of the needle, pressure was placed on the injection site.

All patients' age, body mass index, symptoms, duration of symptoms, medications, past surgical history, physical examinations, pain scores $[10-\mathrm{cm}$ visual analogue scale (VAS)], MRI and ultrasound results, and pain management interventions were recorded.

\section{RESULTS}

The demographics of the patients are presented in Table I. Interventions and outcomes are presented in Table II. Eight patients had isolated II neuralgia, two patients had II and GF neuralgia in combination, and seven patients had $\mathrm{II}$ and $\mathrm{IH}$

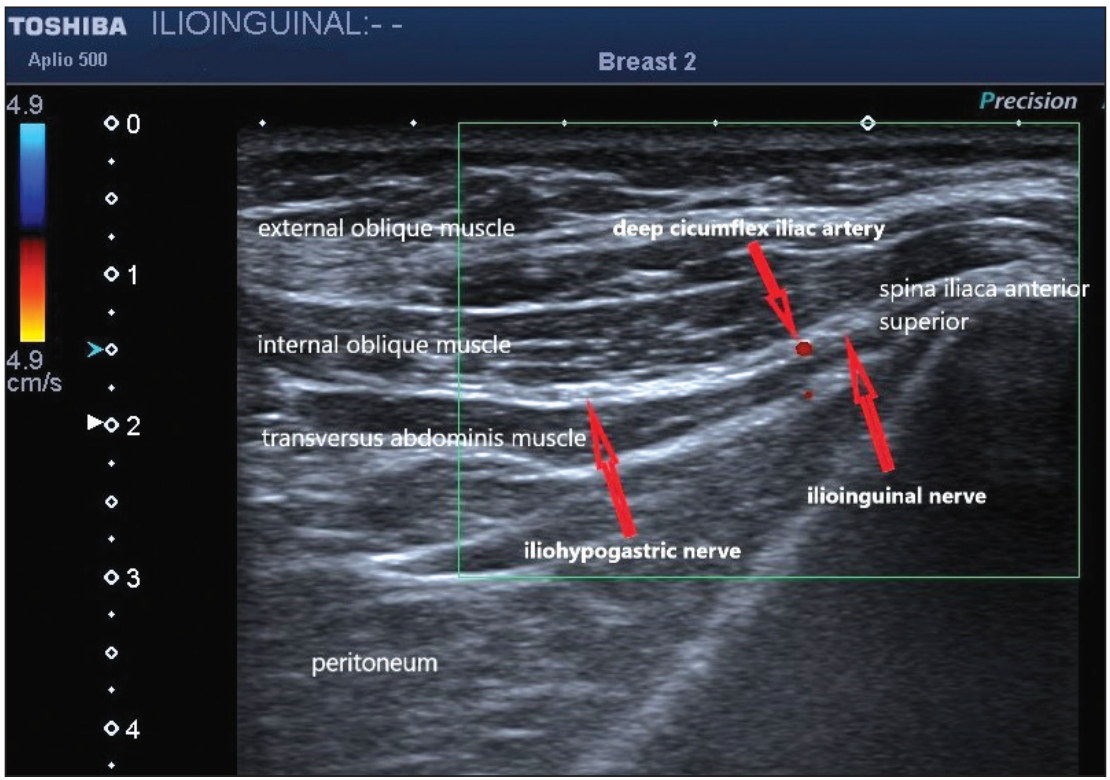

Figure 1: Ultrasound imaging of ilioinguinal and iliohypogastric nerves. 
neuralgia in combination. After careful physical examination and determination of the area of pain, all patients received diagnostic peripheral nerve blocks. Thirteen patients showed good response, and then three consecutive (weekly) therapeutic (with steroid) peripheral nerve blocks were performed. One patient received one and one patient received two series of therapeutic nerve blocks with local anesthetic and corticosteroid. Six patients' symptoms were resolved totally (VAS:0), and pain was improved in the remaining four patients. Three patients were prescribed pregabalin.
Seven patients who had ineffectual peripheral nerve blocks then underwent diagnostic TAP blocks under the guidance of ultrasound. Three patients showed good response and then three consecutive (weekly) therapeutic (with steroid) TAP blocks were performed. Two patients' symptoms were resolved totally (VAS:0), and pain was improved in one patient.

TAP blocks were in effectual in four patients who were then scheduled for selective spinal nerve blocks. Three of these four patients had isolated II neuralgias, and one had II and $\mathrm{IH}$ neuralgia in combination. Therefore, we planned an initial diagnostic T12 and L1 nerve block under fluoroscopy in the

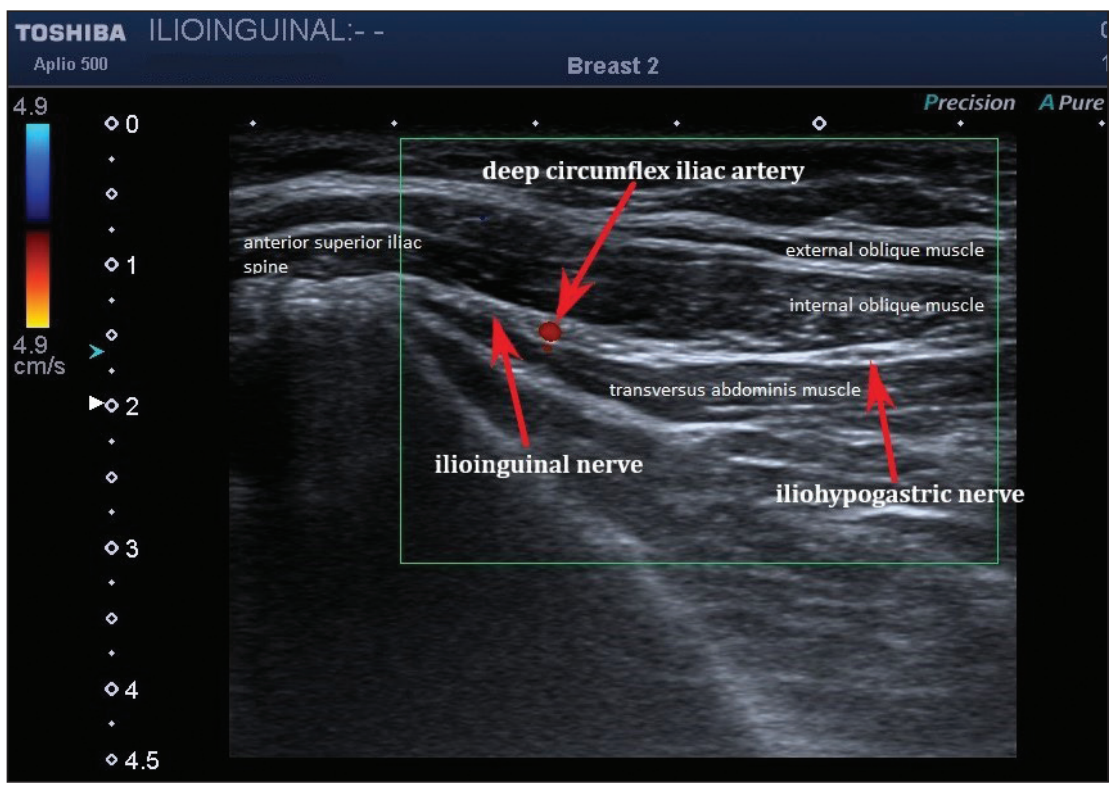

Figure 2: Ultrasound imaging of ilioinguinal and iliohypogastric nerves.

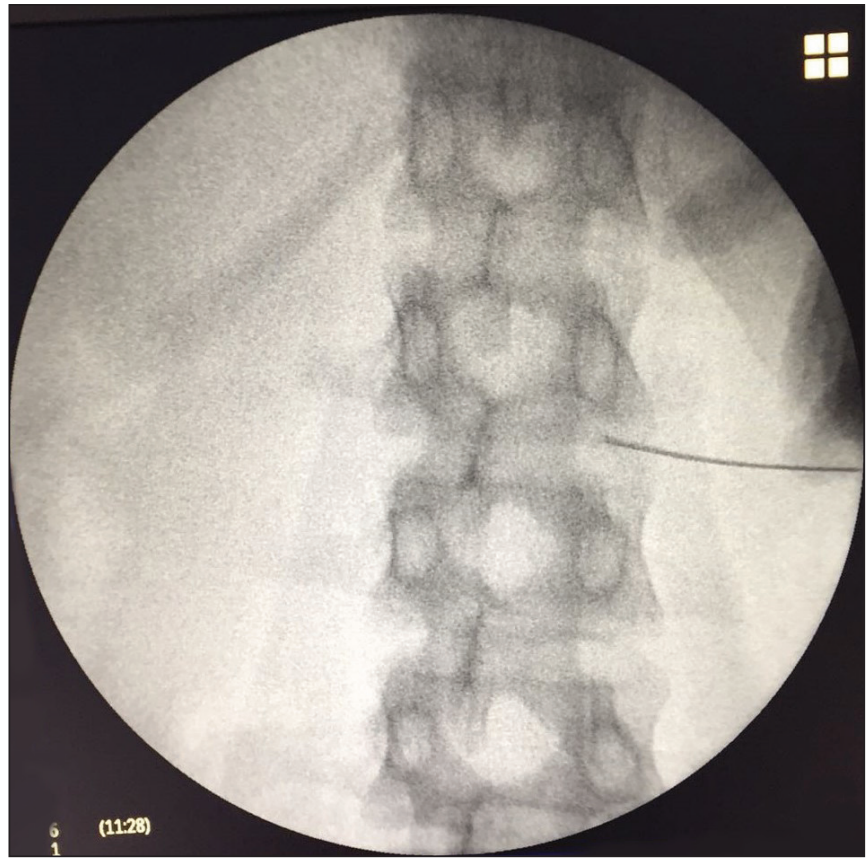

Figure 3: Fluoroscopy AP imaging of needle position (L1).

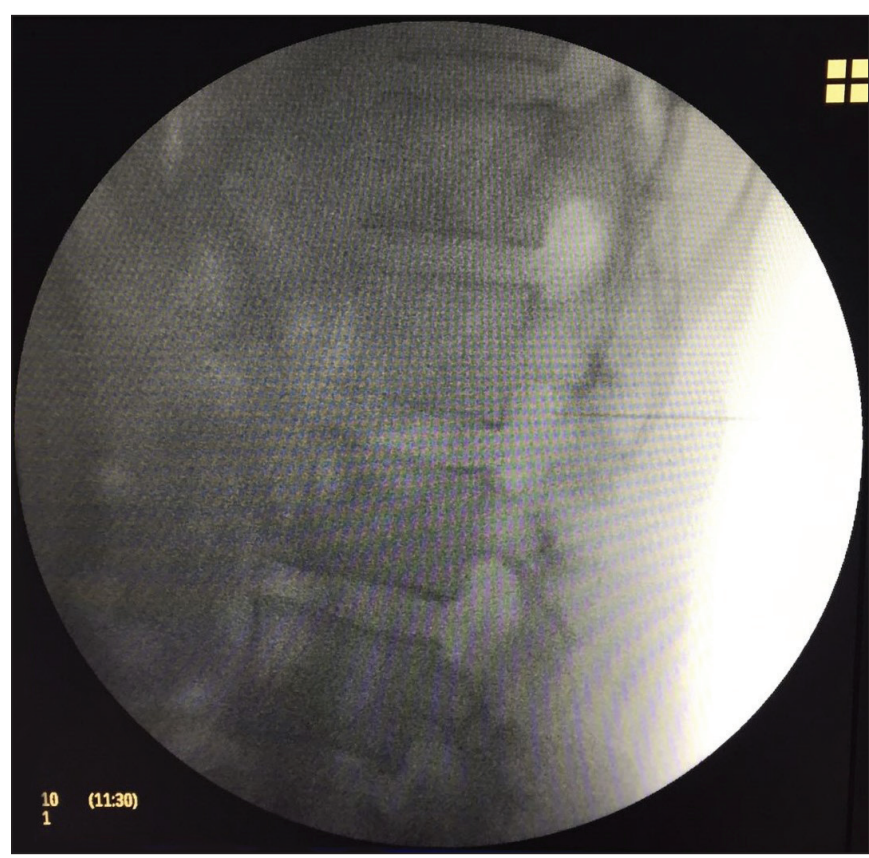

Figure 4: Fluoroscopy lateral imaging of needle position (L1). 


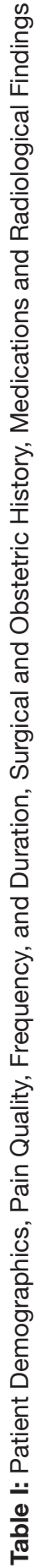

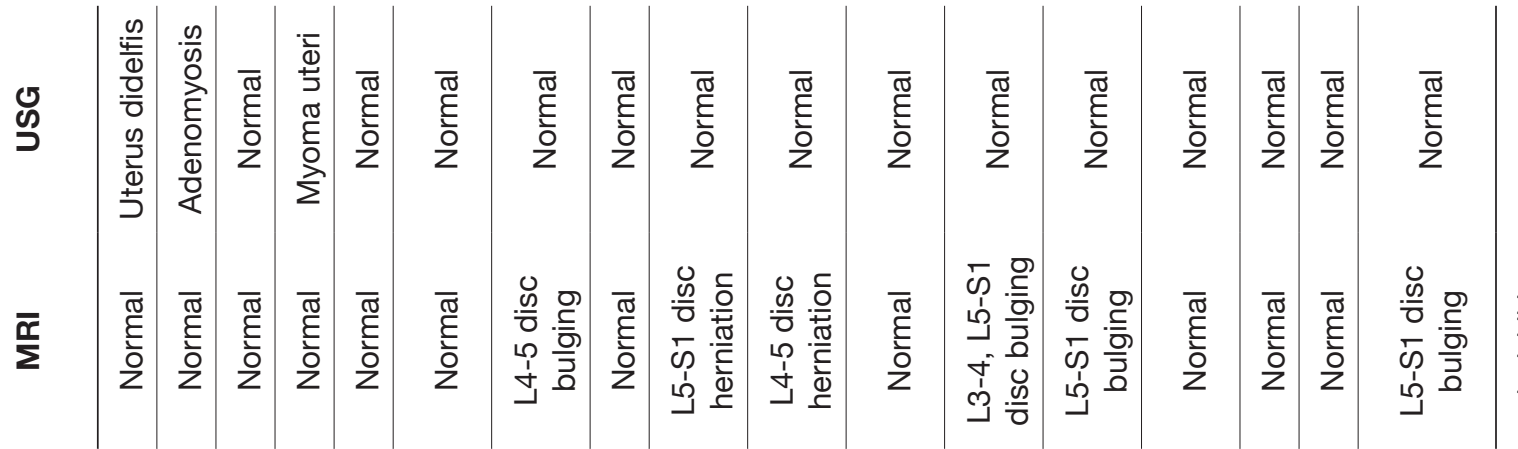

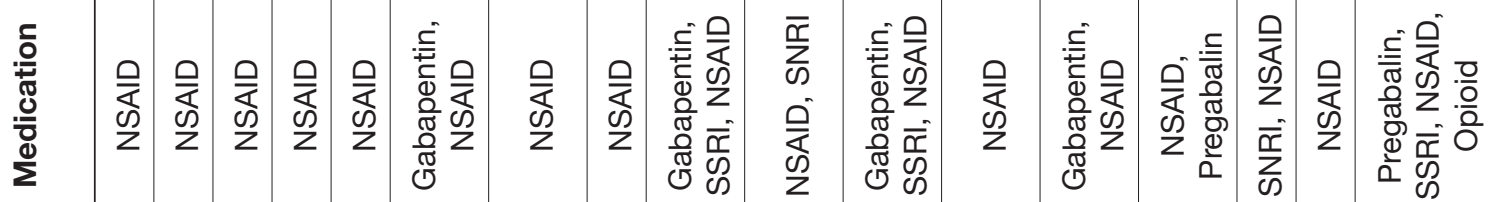

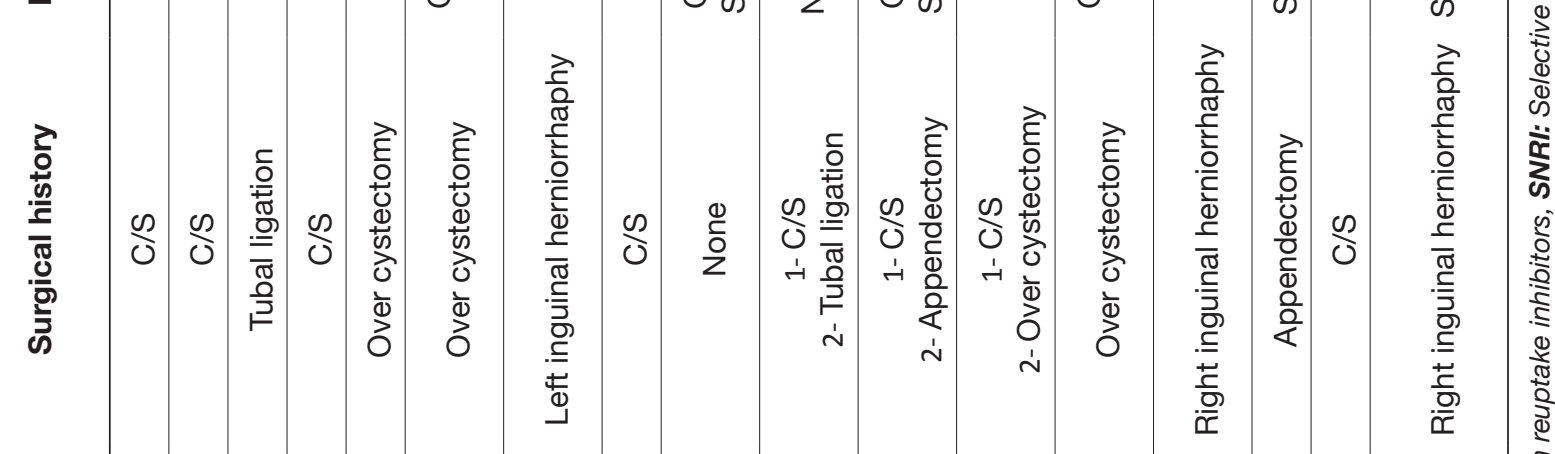

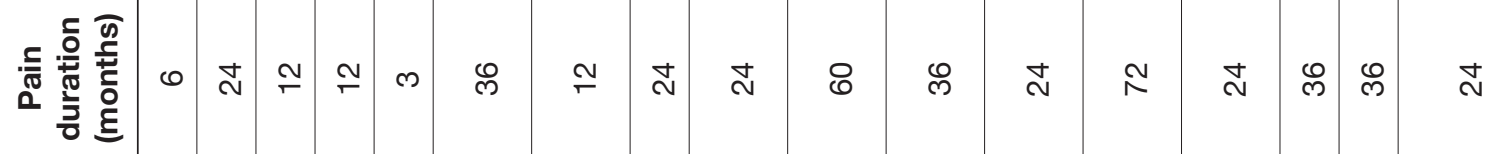

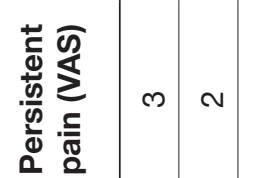

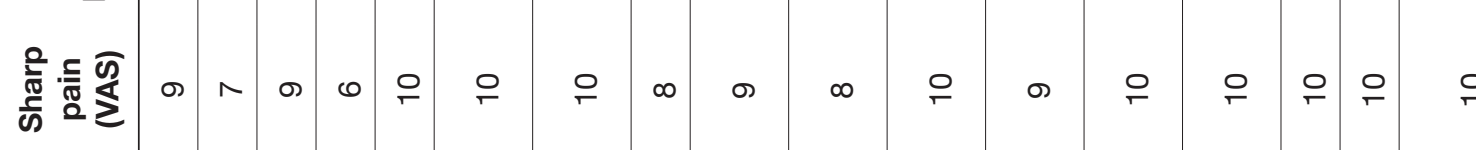

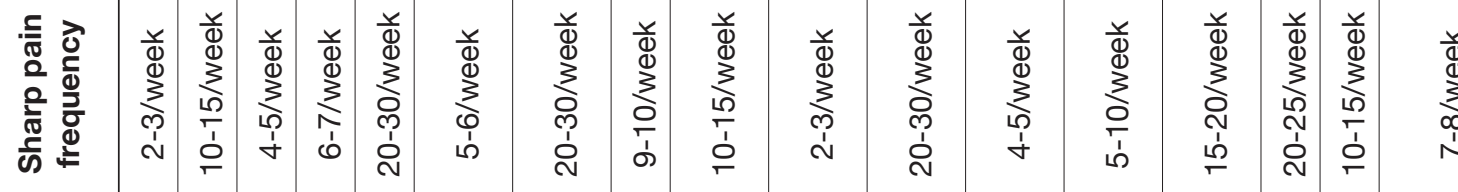

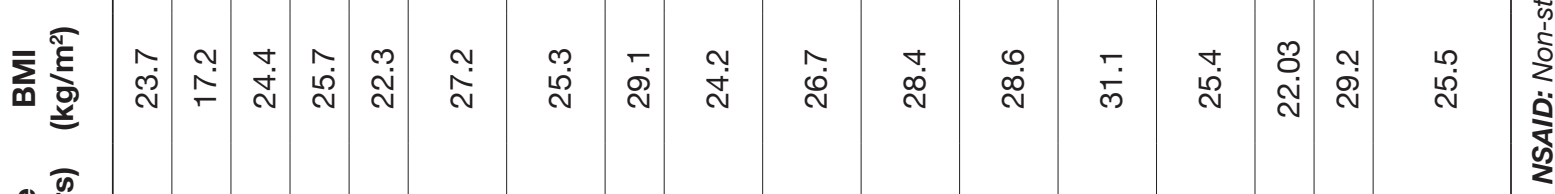

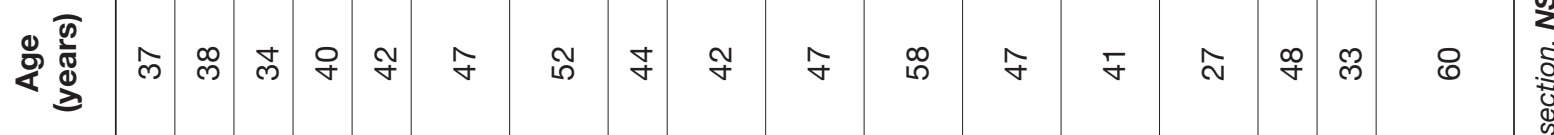

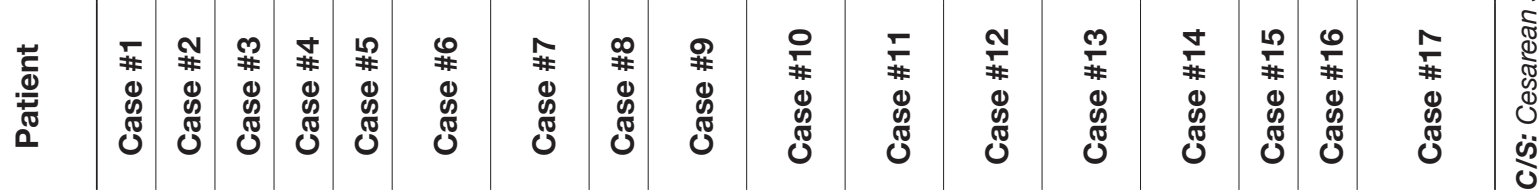


Table II: Injured Nerve, Physical Evaluation, Interventions, and Outcomes

\begin{tabular}{|c|c|c|c|c|c|c|c|}
\hline Patient & Neuralgia & $\begin{array}{c}\text { Physical } \\
\text { examination } \\
\text { findings at the } \\
\text { nerves' respective } \\
\text { cutaneous } \\
\text { innervations }\end{array}$ & $\begin{array}{c}\text { Nerve block } \\
\text { (diagnostic } \\
\text { + series) }\end{array}$ & $\begin{array}{c}\text { TAP block } \\
\text { (diagnostic + } \\
\text { series) }\end{array}$ & $\begin{array}{c}\text { Selective } \\
\text { spinal nerve } \\
\text { block (T12-L1) } \\
\text { (diagnostic + } \\
\text { series) }\end{array}$ & $\begin{array}{c}\text { Follow-up } \\
\text { after the } \\
\text { last block } \\
\text { (months) }\end{array}$ & Outcomes \\
\hline Case \#1 & $\begin{array}{l}\text { Left II and } \\
\text { GF }\end{array}$ & Paresthesia & $1+3$ & 0 & 0 & 19 & Painless \\
\hline Case \#2 & $\begin{array}{l}\text { Right II and } \\
\text { GF }\end{array}$ & $\begin{array}{l}\text { Hypoesthesia, } \\
\text { paresthesia }\end{array}$ & $1+3$ & 0 & 0 & 18 & $\begin{array}{c}\text { No persistent pain, } \\
\text { seldom sharp pain (1-2/ } \\
\text { month; VAS:4) }\end{array}$ \\
\hline Case \#3 & Right II & Hypoesthesia & $1+2$ & 0 & 0 & 12 & Painless \\
\hline Case \#4 & Right II & Hypoesthesia & $1+3$ & 0 & 0 & 19 & Painless \\
\hline Case \#5 & Left II & Hypoesthesia & $1+1$ & 0 & 0 & 10 & Painless \\
\hline Case \#6 & Right II & Hypoesthesia & $1+3$ & 0 & 0 & 10 & Painless \\
\hline Case \#7 & Left II and IH & $\begin{array}{l}\text { Hyperesthesia, } \\
\text { paresthesia }\end{array}$ & $1+3$ & 0 & 0 & 10 & $\begin{array}{c}\text { Persistent pain } \\
\text { VAS:1, no sharp } \\
\text { pain. Prescribed to } \\
\text { pregabalin. }\end{array}$ \\
\hline Case \#8 & $\begin{array}{c}\text { Right II and } \\
\text { IH }\end{array}$ & Hyperalgesia & $1+3$ & 0 & 0 & 20 & $\begin{array}{c}\text { No persistent pain, } \\
\text { sharp pain frequency } \\
\text { decreased (3-4/month; } \\
\text { VAS:6) Prescribed to } \\
\text { pregabalin. }\end{array}$ \\
\hline Case \#9 & $\begin{array}{c}\text { Right II and } \\
\text { IH }\end{array}$ & Hypoesthesia & $1+3$ & 0 & 0 & 9 & $\begin{array}{c}\text { No persistent pain, } \\
\text { sharp pain frequency } \\
\text { decreased (4-5/month; } \\
\text { VAS:5) Prescribed to } \\
\text { pregabalin. }\end{array}$ \\
\hline Case \#10 & $\begin{array}{c}\text { Right II and } \\
\text { IH }\end{array}$ & Hypoesthesia & $1+3$ & 0 & 0 & 15 & Painless \\
\hline Case \#11 & Right II & $\begin{array}{l}\text { Hyperalgesia, } \\
\text { paresthesia }\end{array}$ & $1+0$ & $1+3$ & 0 & 6 & Painless \\
\hline Case \#12 & $\begin{array}{c}\text { Right II and } \\
\text { IH }\end{array}$ & Hypoesthesia & $1+0$ & $1+2$ & 0 & 6 & Painless \\
\hline Case \#13 & $\begin{array}{c}\text { Right II and } \\
\text { IH }\end{array}$ & $\begin{array}{l}\text { Hyperalgesia, } \\
\text { paresthesia }\end{array}$ & $1+0$ & $1+4$ & 0 & 6 & $\begin{array}{l}\text { Persistent pain VAS:1, } \\
\text { no sharp pain. }\end{array}$ \\
\hline Case \#14 & $\begin{array}{c}\text { Right II and } \\
\text { IH }\end{array}$ & $\begin{array}{c}\text { Allodynia, } \\
\text { hyperalgesia }\end{array}$ & $1+0$ & $1+0$ & $1+3$ & 10 & $\begin{array}{c}\text { No persistent pain, } \\
\text { sharp pain frequency } \\
\text { decreased (1-2/month; } \\
\text { VAS:3) }\end{array}$ \\
\hline Case \#15 & Left II & $\begin{array}{l}\text { Hyperalgesia, } \\
\text { paresthesia }\end{array}$ & $1+0$ & $1+0$ & $1+1$ & 13 & Painless \\
\hline Case \#16 & Left II & $\begin{array}{l}\text { Hyperalgesia, } \\
\text { paresthesia }\end{array}$ & $1+0$ & $1+0$ & $1+1$ & 15 & Painless \\
\hline Case \#17 & Right II & $\begin{array}{l}\text { Hyperesthesia, } \\
\text { paresthesia }\end{array}$ & $1+0$ & $1+0$ & $1+2$ & 13 & $\begin{array}{c}\text { No persistent pain, } \\
\text { seldom sharp pain }(0-1 / \\
\text { month; VAS:4) }\end{array}$ \\
\hline
\end{tabular}


operating room. All four patients had good response to this proximal level nerve block. Following a positive diagnostic nerve block, two patients received one therapeutic nerve block, which resulted in total pain relief. One patient received two series (monthly) of injections and pain was improved. One patient (Case \#14), who received a series of three therapeutic injections only when her symptoms increased, received injections over increasing periods of time (i.e. one month between injections one and two, and three months between injections two and three), and she reported that her pain was significantly improved. No major complications related to the blocks were observed. There was a transient reduction in hip flexion in the fourth nerve block of Case \#14 and in the third nerve block of Case \#17.

\section{DISCUSSION}

Chronic postsurgical pain has been defined as pain that develops after surgical intervention, lasts for at least two months, and other causes of pain have been excluded (21). Mastectomy, thoracotomy, major abdominal surgery, and lumbar spine surgery have all been shown to have higher rates of chronic postsurgical pain $(9,11)$. Chronic postsurgical groin pain has been reported in $63 \%$ of cases and is an important measure of clinical outcome (19). Moderate-to-severe pain affects the physical activity, social interactions, and life quality of patients. Common sources of groin pain include mechanical damage, perineural scarring or entrapment (scar tissue, mesh, or sutures) of nerves during lower abdominal surgeries, tissue inflammation, lumbar plexus pathologies, and T12, L1, L2 radiculopathies $(25,26)$. Similarly, 16 of our 17 patients' symptoms were associated with surgery; one patient (Case \#9) had no past surgical history. After excluding all potential causes, we concluded the groin pain of the Case \#9 was associated with pregnancy, which may be due to the tension of the abdominal muscles during pregnancy.

Treatment is often challenging, and no definitive treatment algorithm exists. Multidisciplinary management of this complex problem improves outcomes because treatment must be individualized. Although most patients can be managed with pharmacologic and interventional techniques, operative management is sometimes necessary (10). For pharmacologic treatment, it is important to choose medication according to factors including potential adverse effects, concomitant treatment of other comorbidities (anxiety, depression, and insomnia), drug interactions, risk of abuse, patient adherence to medication, and cost (5). In various pain conditions, the adverse effects of drugs and concerns related with long-term treatment limit their chronic use.

For interventional pain management, peripheral nerve blocks are necessary to show the affected nerves and demonstrate the location of nerve damage (8). To show the location of the nerve injury, local anesthetic must be administered to proximal to the site of injury. However, peripheral nerve blocks using a blind technique with anatomic landmarks as guidance for needle placement are mostly successful, but the guidance of ultrasound, computed tomography, and MR will surely increase the success rate $(14,24,27,29)$. If peripheral nerve block at the distal part of the nerve is in effective, more proximal lesions should be considered. Ten of our 17 patients had satisfactory results with peripheral nerve blocks with blind or ultrasoundguided techniques. Seven patients did not respond to distal nerve blocks, then TAP blocks were performed. Three of seven patients had good results with TAP blocks. Selective spinal nerve block under fluoroscopy was performed in the four patients who did not respond to TAP blocks, and all four patients had good results.

As far as we can as certain, there is no literature related with selective spinal nerve block for in effective peripheral $\mathrm{II}, \mathrm{IH}$, and GF nerve blocks. Many studies report triple neurectomy of these three nerves for the surgical management of refractory neuropathic groin pain with high success rates of $85 \%$ to $97 \%(1,10,32)$. Although, selective spinal nerve blocks are also associated with complications (20), they can be safely performed under guidance of fluoroscopy even in patients with spinal deformities (17). A major transient problem with these blocks is inappropriate spreading of local anesthetics (18). These undesirable outcomes are preventable with advancing technology, such as MR neurography-guided nerve blocks (15). In our reviewed clinical experience, we encountered no major complications, but we observed transient reduction in hip flexion in two of the nerve blocks, which could be the result of the spread of local anesthetic to the lumbar plexus.

The limitation of this study is the small number of patients. More randomized controlled studies with larger numbers of patients are needed to show the advantages and disadvantages of upper level nerve blocks in II, IH, and GF neuralgias. Before deciding on surgery, all preceding steps must be taken for the management of pain, and treatment modalities must be individualized.

\section{CONCLUSION}

If distal peripheral nerve blocks are ineffective, an upper level nerve lesion should be considered in ilioinguinal, iliohypogastric, and genitofemoral neuralgias. Upper level nerve blocks should be performed before deciding on surgery.

\section{ACKNOWLEDGEMENT}

The authors express their gratitude to Professor Sacit Gulec, Eskisehir Osmangazi University, Department of Algology, and Professor Tuncay Colak, Kocaeli University, Department of Anatomy for their valuable reviews and comments on aspects of this manuscript.

\section{REFERENCES}

1. Acar F, Ozdemir M, Bayrakli F, Cirak B, Coskun E, Burchiel $\mathrm{K}$ : Management of medically intractable genitofemoral and ilioingunal neuralgia. Turk Neurosurg 23:753-757, 2013

2. Anloague PA, Huijbregts P: Anatomical variations of the lumbar plexus: A descriptive anatomy study with proposed clinical implications. J Man Manip Ther 17: 107-114, 2010 
3. Attal N, Cruccu G, Baron R, Haanpää M, Hansson P, Jensen TS, Nurmikko T: European Federation of Neurological Societies. EFNS guidelines on the pharmacological treatment of neuropathic pain: 2010 revision. Eur J Neurol 17:11131188, 2010

4. Bachul P, Tomaszewski KA, Kmiotek EK, Kratochwil M, Solecki $\mathrm{R}$, Walocha JA: Anatomic variability of groin innervation. Folia Morphol (Warsz) 72: 267-270, 2013

5. Bjurstrom MF, Nicol AL, Amid PK, Chen DC: Pain control following inguinal herniorrhaphy: Current perspectives. J Pain Res 29: 277-290, 2014

6. Bohrer JC, Walters MD, Park A, Polston D, Barber MD: Pelvic nerve injury following gynecologic surgery: A prospective cohort study. Am J Obstet Gynecol 201:531.e1-7, 2009

7. Cardosi RJ, Cox CS, Hoffman MS: Postoperative neuropathies after major pelvic surgery. Obstet Gynecol 100:240-244, 2002

8. Cesmebasi A, Yadav A, Gielecki J, Tubbs RS, Loukas M: Genitofemoral neuralgia: A review. Clin Anat 28:128-135, 2015

9. Chan CW, Peng P: Failed back surgery syndrome. Pain Med 12:577-606, 2011

10. Chen DC, Hiatt JR, Amid PK: Operative management of refractory neuropathic inguinodynia by a laparoscopic retroperitoneal approach. JAMA Surg 148:962-967, 2013

11. Eisenach JC: Preventing chronic pain after surgery: Who, how and when? Reg Anesth Pain Med 31:1-3, 2006

12. Elkins N, Hunt J, Scott KM: Neurogenic pelvic pain. Phys Med Rehabil Clin N Am 28:551-569, 2017

13. Fanelli RD, DiSiena MR, Lui FY, Gersin KS: Cryoanalgesic ablation for the treatment of chronic postherniorrhaphy neuropathic pain. Surg Endosc 17:196-200, 2003

14. Fritz J, Chhabra A, Wang KC, Carrino JA: Magnetic resonance neurography-guided nerve blocks for the diagnosis and treatment of chronic pelvic pain syndrome. Neuroimaging Clin N Am 24: 211-234, 2014

15. Fritz J, Dellon AL, Williams EH, Rosson GD, Belzberg AJ, Eckhauser FE: Diagnostic accuracy of selective 3-T MR neurography-guided retroperitoneal genitofemoral nerve blocks for the diagnosis of genitofemoral neuralgia. Radiology 285: 176-185, 2017

16. Giger U, Wente $M N$, Büchler MW, Krähenbühl S, Lerut J, Krähenbühl L: Endoscopic retroperitoneal neurectomy for chronic pain after groin surgery. Br J Surg 96:1076-1081, 2009

17. Irwin A, Khan AL, Fender D, Sanderson PL, Gibson MJ: The role of needle tip position on the accuracy of diagnostic selective nerve root blocks in spinal deformity. Eur Spine J 23 Suppl 1:33-39, 2014
18. Kang S, Yang SN, Kim SH, Byun CW, Yoon JS: Ultrasoundguided cervical nerve root block: Does volume affect the spreading pattern? Pain Med 17:1978-1984, 2016

19. Kehlet $\mathrm{H}$ : Chronic pain after groin hernia repair. Br J Surg 95: 135-136, 2008

20. Kumar N: Spinal cord injury complicating a thoracolumbar selective nerve root block in a deformed spine: Neurological and functional outcome. Spinal Cord 53:3-5, 2015

21. Macrae WA, Davies HTO: Chronic postsurgical pain. In: Crombie IK (ed). Epidemiology of Pain. Seattle: IASP Press, 1999:125-142

22. Mitra R, Zeighami A, Mackey S: Pulsed radiofrequency for the treatment of chronic ilioinguinal neuropathy. Hernia 11:369371,2007

23. Nagpal AS, Moody EL: Interventional management for pelvic pain. Phys Med Rehabil Clin N Am 28:621-646, 2017

24. Peng PW, Tumber PS: Ultrasound-guided interventional procedures for patients with chronic pelvic pain - a description of techniques and review of literature. Pain Physician 11:215224, 2008

25. Rauchwerger JJ, Giordano J, Rozen D, Kent JL, Greenspan J, Closson CW: On the therapeutic viability of peripheral nerve stimulation for ilioinguinal neuralgia: Putative mechanisms and possible utility. Pain Pract 8:138-143, 2008

26. Shin JH, Howard FM: Abdominal wall nerve injury during laparoscopic gynecologic surgery: Incidence, risk factors, and treatment outcomes. J Minim Invasive Gynecol 19:448-453, 2012

27. Suresh S, Patel A, Porfyris S, Ryee MY: Ultrasound-guided serial ilioinguinal nerve blocks for management of chronic groin pain secondary to ilioinguinal neuralgia in adolescents. Paediatr Anaesth 18:775-778, 2008

28. Treede RD, Jensen TS, Campbell JN, Cruccu G, Dostrovsky JO, Griffin JW, Hansson P, Hughes R, Nurmikko T, Serra J: Neuropathic pain: Redefinition and a grading system for clinical and research purposes. Neurology 70:1630-1635, 2008

29. Wadhwa V, Scott KM, Rozen S, Starr AJ, Chhabra A: CT-guided perineural injections for chronic pelvic pain. Radiographics 36:1408-1425, 2016

30. Waldman SD: Atlas of Interventional Pain Management. 4th ed. Saunders, 2015:431-446

31. Walter J, Reichart R, Vonderlind C, Kuhn SA, Kalff R: Neuralgia of the genitofemoral nerve after hernioplasty. Therapy by peripheral nerve stimulation. Chirurg 80:741-744, 2009

32. Zannoni M, Luzietti E, Viani L, Nisi P, Caramatti C, Sianesi M: Wide resection of inguinal nerves versus simple section to prevent postoperative pain after prosthetic inguinal hernioplasty: Our experience. World J Surg 38:1037-1043, 2014 